\title{
Rainfall Fluctuation and Region wise Classification in Tamilnadu: Using Geographical Information System
}

\author{
R. Lakshmi Priya ${ }^{1}$ and G. Manimannan ${ }^{2}$ \\ ${ }^{1}$ Assistant Professor, Department of Statistics, Dr. Ambedkar Govt. Arts College, Vysarpadi, Chennai. \\ ${ }^{2}$ Assistant Professor, Department of Statistics, Madras Christian College, Chennai
}

\begin{abstract}
The present research is aimed at analyzing rainfall pattern and classification to evaluate the district wise data in Tamilnadu and make possible the result in various seasons to understand the climate change. The dataset relates to monthly rainfall from various districts of Tamilnadu in the period of January to December from the Indian Meteorological Department database. The time frame of the data pertaining to the present study is 2004-2010. The salient feature of this study is the application of Factor Analysis, K-means clustering and GIS (Geographical Information System) Map as data mining tools to explore the hidden pattern present in the dataset for each of the study periods. Factor analysis is applied first and the factor scores of extracted factors are used to find initial groups by k-means clustering algorithm. Finally, data mining tools are applied and the groups are identified as rainfall belonging to ER (Excess Rainfall), NR (Normal Rainfall) and DR (Deficient Rainfall). The results of the present study indicate that Data Mining Tools can be used as a feasible tool for the analysis of large set of rainfall data.
\end{abstract}

Keywords: Rainfall, Data mining, Factor Analysis, GIS Map and K-means clustering.

\section{Introduction}

Rainfall is the key climatic inconsistent that governs the regional hydrologic cycle and accessibility of water resources. It is also one of the most composite and difficult elements of the hydrological cycle to understand due to the great range of variation over a wide range of scales both in space and time (French et al.,1992).

In this section we describe the state climate, boundaries and average rainfall of Tamilnadu. In the state situated in the southern part of the country, Tamil Nadu is one of the most well known and important states in India. Andhra Pradesh forms the northern border for it whereas Karnataka and Kerala lie on the North West and west respectively. Two water bodies enclose the state on the southern as well as the eastern sides, the Indian Ocean and the Bay of Bengal respectively. In fact, geometrically, Tamil Nadu touches the acute southern tip of the Indian Peninsula. The climate of Tamilnadu is generally wet subtropical climate and features fairly hot temperature over the year except during the monsoon season. The state has three distinct monsoon periods of rainfall. The south west monsoon starts from the period of June to September with strong southwest winds. The north east monsoon starts from the period of October to December with dominant northeast winds. Finally, dry season starts from January to May. The normal annual rainfall of the state is about $945 \mathrm{~mm}$ (37.2 in) of which $48 \%$ is through the North East monsoon, and 32\% through the South West monsoon. Since the state is fully dependent on rains for recharging its water resources, monsoon failures lead to acute water scarcity and severe drought.

Moreover, factors like climate change and urbanization have also had an impact on the variation in rainfall. Recent studies have stated that any analysis of hydro-climatic variables should be done at the local scale rather than at a large or global scale (Sharma and Shakya, 2006; Barua et al., 2013).

\section{Brief Review Of Literature}

Rainfall is key factor determining the sustainability and conservation of living species on the earth. In dry farming areas, where rainfall is the sources of water for crops, changes in both quantity and distribution of rainfall during the year could affect the economy of an area (M.C.Ramos, 2001). Many researchers have applied MPL (Multi variables Polynomial regression) to implement the precipitation forecast model over Myanmar. The model output result in station wide monthly and annual rainfall amount during summer monsoon season. It is observed that MPR method achieves closer agreement between actual and estimated rainfall.

In this paper attempts have been made to study pattern in annual and classification of rainfall over Tamilnadu from 2004 to 2010. Long term trends of Indian monsoon rainfall for the country as well as for smaller subdivisions were studied by Pramanik and Jagannathan (1954), Parthasarathy and Dhar (1978), Parthasarathy (1984), Mooley and Parthasarathy (1983), Parthasarathy et al. (1993). Rao and Jagannathan (1963), Thapliyal and Kulshrestha (1991) and Srivatsava et al. (1992) also reported that All-India southwest monsoon/annual rainfall observed no significant trend. Long term trend in small spatial scale was reported by 
Koteswaram and Alvi (1969), Jagannathan and Bhalme (1973), Naidu et al. (1999) and Singh and Sontakke (1999). Rupa Kumar et al (1992) have found significant increasing trend in monsoon rainfall along the West Coast, north Andhra Pradesh and northwest India while significant decreasing trends over Madhya Pradesh and adjoining area, northeast India and parts of Gujarat and Kerala. All these studies reveal that there is no similarity in rainfall trends at the regional level. The main objective of the present study is identifying the structural pattern and classification of all the season of rainfall data in Tamil Nadu using the following statistical techniques:

(a) To identify the pattern of rainfall data in the study period using Factor Analysis.

(b) To identify the final cluster centres and classification of rainfall data using $k$ - mean clustering techniques.

(c) To identify the classification Map based on extracted cluster center using Geographical Information System (GIS)

\section{Methodology}

In this section brings out the discussion of the database selected and the Data Mining Techniques.

\subsection{Database And Study Region}

The monthly wise rainfall parameters were recorded in various districts of Tamilnadu. The district wise rainfall data were collected as secondary source from Meteorological Department in India, during the period of 2004 to 2010 was considered as database. Three seasonal rainfall data were chosen for the present research that had been used in previous studies. The data mainly consists of three major categories, such as winter, summer and monsoon seasons.

\subsection{Data Mining Techniques}

Data Mining is an interdisciplinary field, the confluence of a set of disciplines in the following figure, including database systems, Statistics, machine learning, visualization and information science.

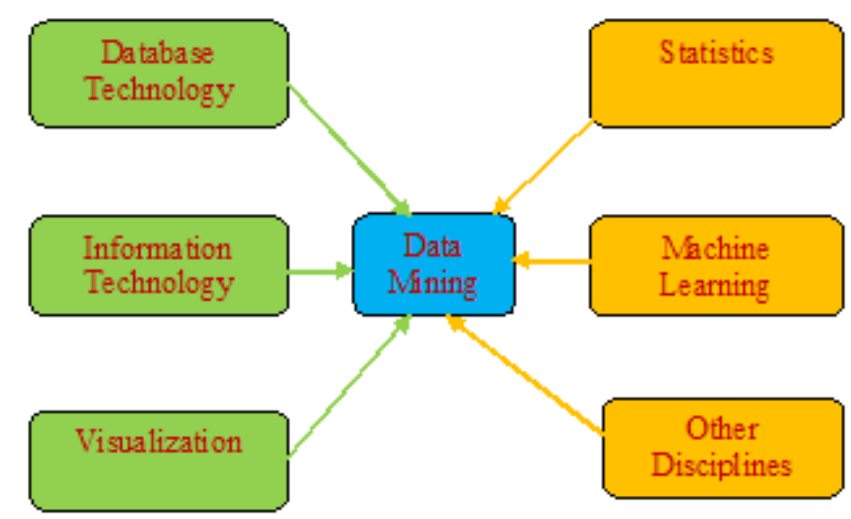

Although data mining is a new term, the technology is not. Data Mining or Knowledge Discovery in Databases (KDD) is the process of discovering previously unknown and potentially useful information from the data in databases. In the present context data mining exhibits the patterns by applying few techniques namely, factor analysis, $k$-means clustering and discriminant rule. As such KDD is an iterative process, which mainly consist of the following steps;

Step 1: Data cleaning;

Step 2: Data Integration;

Step 3: Data selection and transformation;

Step 4: Data Mining and

Step 5: Knowledge representation

Of these above iterative process Steps 4 and 5 are most important. If clever techniques are applied in Step 5, it provides potentially useful information that explains the hidden structure. This structure discovers knowledge that is represented visually to the user, which is the final phase of data mining. 


\subsection{Factor Analysis}

The data to be compressed consist of $N$ data vectors, from $k$-dimensions. Principal Component Analysis (PCA) searches for $c k$ dimensional orthogonal vectors that can best be used to represent the data, where $c \leq k$. The original data set are projected onto a much smaller space, resulting in data compression. PCA can be used as a form of dimensionality deduction. Though, unlike attribute subset selection, which reduces the attribute set size by retaining a subset of the initial set of attributes, PCA "combines" the essence of attributes by creating an alternative, smaller set of variables. The intial data can be projected onto the smaller set. (J. Han M. Kamber, 2002). Factor analysis provides the tools for analyzing the structure of the interrelationships (correlations) among the large number of variables by defining sets of variables that are highly interrelated, known as factors. Factor analysis is initiated to uncover the patterns underlying monthly wise rainfall data. In factor extraction method the number of factors is decided based on the proportion of sample variance explained. Orthogonal rotations such as Varimax and Quartimax rotations are used to measure the similarity of a variable with a factor by its factor loading.

\subsection{K-Means Clustering Methods}

From unsupervised learning the researcher studies (i) no class label (ii) finding common patterns and (iii) grouping similar objects. McQueen (1967) suggests the term $k$-means for describing an algorithm of his that assigns item to the cluster having the nearest centroid (mean). Generally this technique uses Euclidean distances measures computed by variables. Since the group labels are unknown for the data set, k-means clustering is one such technique in applied statistics that discovers acceptable meaningful classes or groups.

\subsection{Geographical Information System}

In the present study, GIS map is used to exhibit groups graphically and judge the nature of overall structural pattern of the rainfall data.

\section{Algorithms}

A brief algorithm to classify the rainfall data during each of the study period based on their overall performance is described below:

Step 1: Factor analysis is initiated to find the structural pattern underlying the data set.

Step 2: $k$-means clustering techniques partitioned the data set into $k$-clusters using year wise rainfall data as input matrix.

Step 3: Construct a Map using GIS and the final cluster centered (mean) values with the entire districts of Tamilnadu rainfall data set that are assigned group labels in step 2.

\section{Results And Discussion}

As mentioned in Section 3.3 Varimax and Quartimax criterion for orthogonal rotation have been used for the pruned data. Even though the results obtained by both the criterions were very similar, the varimax rotation provided relatively better clustering of rainfall data. Consequently, only the results of varimax rotation are reported here. We have decided to retain 75 to 80 percent of total variation in the data, and thus accounted consistently four factors for 2004, 2005 and 2010, the remaining years consistently three factors for each year with eigen values little less than or equal to unity. Table 1 and 2 shows variance accounted for each factors.

Table 1. Percentage of variance explained by factors

\begin{tabular}{|c|c|c|c|}
\hline Factors & $\mathbf{2 0 0 4}$ & $\mathbf{2 0 0 5}$ & $\mathbf{2 0 0 6}$ \\
\hline 1 & 30.734 & 27.235 & 30.194 \\
2 & 22.359 & 23.128 & 23.477 \\
3 & 17.806 & 13.725 & 16.552 \\
4 & 8.822 & 9.361 & 0.000 \\
\hline Total & $\mathbf{7 9 . 7 2}$ & $\mathbf{7 5 . 4 9}$ & $\mathbf{7 0 . 2 2}$ \\
\hline
\end{tabular}

Table 2. Percentage of Variance explained by factors

\begin{tabular}{|c|c|c|c|c|}
\hline Factors & $\mathbf{2 0 0 7}$ & $\mathbf{2 0 0 8}$ & $\mathbf{2 0 0 9}$ & $\mathbf{2 0 1 0}$ \\
\hline 1 & 30.409 & 33.480 & 32.962 & 33.260 \\
2 & 27.609 & 26.369 & 28.351 & 22.195 \\
3 & 16.250 & 17.792 & 13.906 & 16.213 \\
4 & 0.000 & 0.000 & 0.000 & 9.859 \\
\hline Total & $\mathbf{7 4 . 2 6}$ & $\mathbf{7 7 . 6 4}$ & $\mathbf{7 5 . 2 1}$ & $\mathbf{8 1 . 5 2}$ \\
\hline
\end{tabular}


From the above table we observe that the total variances explained by the extracted factors are over 75 percent, which are relatively higher. For each factors the variability is more or less the same for the study period.

The monthly wise data loaded in the factors are presented in Table 3 (2004 to 2010). Only those months with higher loadings are indicated by red color. From the Table 4 it is clear that the clustering of rainfall is stable and unstable during the study period. We observed slight changes in factor loadings during the periods considered. The differences in factor loadings may be due to statistical variations in the original data. In each year the factors are loaded depend upon the seasonal rainfall; we named the factors like, summer factor, winter factor and monsoon factor.

Table 3. Rotated factor matrix for Rainfall data ( 2004 to 2010)

\begin{tabular}{|l|c|c|c|c|}
\hline \multirow{2}{*}{ Months } & \multicolumn{4}{|c|}{$\mathbf{2 0 0 4}$ Component } \\
\cline { 2 - 5 } & 1 & 2 & 3 & 4 \\
\hline December & .859 & -.013 & -.219 & .157 \\
November & .851 & .401 & .103 & -.074 \\
October & .850 & .220 & .364 & -.052 \\
April & -.580 & .406 & -.254 & .224 \\
June & -.257 & .876 & .208 & -.024 \\
August & .217 & .805 & .289 & -.114 \\
January & .259 & .717 & -.097 & .008 \\
May & .116 & .162 & .843 & .359 \\
September & .336 & .184 & .790 & .067 \\
February & .280 & .515 & -.616 & .335 \\
July & -.506 & .087 & .614 & .401 \\
March & .029 & .094 & -.226 & -.848 \\
\hline
\end{tabular}

\begin{tabular}{|l|c|c|c|c|}
\multicolumn{1}{|c|}{$\mathbf{2 0 0 7}$} \\
\hline \multirow{2}{*}{ Months } & \multicolumn{4}{c|}{ Component } \\
& 1 & 2 & 3 & 4 \\
\hline July & .923 & .256 & -.001 & .060 \\
June & .901 & .130 & -.140 & -.026 \\
August & .749 & -.463 & .238 & -.133 \\
April & .079 & .794 & -.028 & -.056 \\
January & .348 & .726 & -.107 & -.167 \\
February & -.306 & .564 & -.381 & -.085 \\
November & -.223 & .018 & .820 & .148 \\
March & -.080 & .235 & -.707 & -.197 \\
September & .434 & -.361 & .677 & -.027 \\
May & .115 & -.318 & -.431 & -.370 \\
October & .177 & -.299 & .056 & .884 \\
December & -.175 & .003 & .276 & .858 \\
\hline
\end{tabular}

\begin{tabular}{|l|c|c|c|}
\hline \multirow{2}{*}{ Months } & \multicolumn{3}{|c|}{ Component } \\
\cline { 2 - 4 } & 1 & 2 & 3 \\
\hline June & .881 & -.087 & .072 \\
July & .857 & .220 & .294 \\
May & .716 & .007 & -.529 \\
September & .705 & -.335 & .067 \\
August & .648 & -.461 & .174 \\
January & -.032 & .909 & .077 \\
November & -.178 & .773 & .435 \\
February & -.096 & .698 & .013 \\
March & -.065 & .675 & -.432 \\
December & .100 & .021 & .831 \\
October & .127 & .389 & .771 \\
April & -.073 & .141 & -.646 \\
\hline
\end{tabular}

\begin{tabular}{|l|c|c|c|}
\hline \multirow{2}{*}{ Months } & \multicolumn{3}{|c|}{ Component } \\
\cline { 2 - 4 } & 1 & 2 & 3 \\
\hline December & .896 & .001 & -.033 \\
April & -.894 & .201 & .094 \\
October & .702 & .244 & .378 \\
March & -.673 & .555 & .319 \\
May & -.531 & .378 & -.461 \\
September & -.088 & .878 & -.079 \\
July & .122 & .859 & -.056 \\
June & -.266 & .850 & .093 \\
August & .580 & .631 & -.357 \\
November & .037 & .072 & .832 \\
January & -.225 & -.294 & .615 \\
February & .460 & .403 & .524 \\
\hline
\end{tabular}




\begin{tabular}{|c|c|c|c|c|c|c|c|}
\hline \multicolumn{4}{|c|}{2006} & \multicolumn{4}{|c|}{2009} \\
\hline \multirow{2}{*}{ Months } & \multicolumn{3}{|c|}{ Component } & \multirow{2}{*}{ Months } & \multicolumn{3}{|c|}{ Component } \\
\hline & 1 & 2 & 3 & & 1 & 2 & 3 \\
\hline June & .910 & .246 & .034 & December & .950 & -.147 & .102 \\
\hline July & .880 & .204 & -.291 & January & .933 & -.106 & -.041 \\
\hline September & .782 & -.235 & .130 & November & .858 & .235 & -.052 \\
\hline August & .652 & -.120 & -.523 & March & .615 & .575 & -.202 \\
\hline March & -.202 & .914 & .057 & June & -.219 & .881 & .215 \\
\hline October & .234 & .844 & .039 & July & -.040 & .854 & .198 \\
\hline February & .414 & .725 & -.152 & October & .422 & .755 & -.254 \\
\hline April & -.074 & .629 & -.611 & May & -.526 & .567 & .233 \\
\hline May & .422 & -.569 & -.399 & August & .161 & .474 & .734 \\
\hline November & -.174 & -.051 & .913 & September & -.451 & .265 & .674 \\
\hline January & .098 & -.007 & .894 & April & .257 & .313 & -.673 \\
\hline December & -.347 & .442 & .579 & February & -.117 & -.071 & -.636 \\
\hline
\end{tabular}

\begin{tabular}{|c|c|c|c|c|}
\hline \multicolumn{5}{|c|}{2010} \\
\hline & \multicolumn{4}{|c|}{ Component } \\
\hline & 1 & 2 & 3 & 4 \\
\hline August & .887 & -.117 & .155 & .242 \\
\hline June & .845 & .296 & .054 & .199 \\
\hline July & .771 & .337 & -.269 & .328 \\
\hline September & .702 & -.137 & .145 & -.359 \\
\hline February & .679 & .557 & -.170 & -.251 \\
\hline April & -.141 & .891 & -.138 & .089 \\
\hline March & .357 & .867 & -.015 & .061 \\
\hline October & .109 & .645 & .388 & .057 \\
\hline December & .164 & -.260 & .901 & .068 \\
\hline November & -.041 & .020 & .859 & -.126 \\
\hline January & -.035 & .204 & .836 & -.094 \\
\hline May & .157 & .084 & -.107 & .936 \\
\hline
\end{tabular}

\section{Red color Indicates rainfall data loaded in respective factors}

After performing factor analysis, the next stage is to assign initial group labels to each year. Step 2 of the algorithm is explored with rainfall data by Step 1, by conventional $k$-means clustering analysis. Formations of clusters are explored by considering 2-clusters, 3-clusters, 4-cluster and so on. Out of all the possible trials, 3cluster exhibited meaningful interpretation than two, four and higher clusters. Having decided to consider only 3 clusters, it is possible to tempo a rainfall as group ER, group NR or group DR depending on whether the rainfall belonged to Cluster 1, Cluster 2 or Cluster 3 respectively. Cluster 1 (group ER) is a group of rainfall that have excess rainfall from the rainfall data, indicating that these years have excess rain. The years with deficient rainfall are grouped into Cluster 3 (Group DR). This suggested that Cluster 3 is a group of years with deficient rainfall. Cluster 2 (Group NR) are those years which received normal rainfall when compared to Cluster 1 and Cluster 3. In spite of incorporating the results for each year, only the summary statistics are reported in Table 4.

Table 4 indicates that majority of rainfall are in the monsoon seasons category except for the year 2004. The possible reasons that climate change, earthquake in Indian Ocean. Excess Rainfall in the year 2004 may be due to the reason for climate change in Tamilnadu coastal area. Figure 1 to 7 shows the groupings of rainfall into 3 clusters for each year of the study period. It is interesting to note that the mean vectors of these clusters can be arranged in the up and down order of magnitude as shown in Table 1 to 7. 
Rainfall Fluctuation and Classification over Tamilnadu Region: Using Data Mining Techniques

Table 1. Category of Rainfall data with Cluster Centers

\begin{tabular}{|c|c|c|c|}
\hline \multirow{2}{*}{$\begin{array}{l}\text { Factor } \\
\text { Scores }\end{array}$} & \multicolumn{3}{|c|}{2004} \\
\hline & 1 & 2 & 3 \\
\hline January & 11 & 11 & 7 \\
\hline February & 7 & 1 & 2 \\
\hline March & 7 & 5 & 4 \\
\hline April & 45 & 2 & 35 \\
\hline May & 92 & 322 & 270 \\
\hline June & 18 & 22 & 57 \\
\hline July & 23 & 29 & 79 \\
\hline August & 16 & 76 & 32 \\
\hline September & 103 & 11 & 238 \\
\hline October & 167 & 1 & 245 \\
\hline November & 142 & 5 & 157 \\
\hline December & 13 & 2 & 10 \\
\hline Total & 07 & 04 & 19 \\
\hline
\end{tabular}

Table 3. Category of Rainfall data with Cluster Centers

\begin{tabular}{|c|c|c|c|}
\hline \multirow{2}{*}{$\begin{array}{l}\text { Factor } \\
\text { Scores }\end{array}$} & \multicolumn{3}{|c|}{2006} \\
\hline & 1 & 2 & 3 \\
\hline January & 8 & 17 & 28 \\
\hline February & 0 & 0 & 0 \\
\hline March & 45 & 23 & 89 \\
\hline April & 38 & 17 & 37 \\
\hline May & 69 & 30 & 66 \\
\hline June & 50 & 60 & 63 \\
\hline July & 10 & 53 & 39 \\
\hline August & 72 & 80 & 59 \\
\hline September & 120 & 128 & 103 \\
\hline October & 193 & 484 & 318 \\
\hline November & 157 & 286 & 284 \\
\hline December & 15 & 70 & 28 \\
\hline Total & 16 & 05 & 09 \\
\hline
\end{tabular}

Table 5. Category of Rainfall data with Cluster Centers

\begin{tabular}{|c|c|c|c|}
\hline \multirow{2}{*}{\begin{tabular}{|l|} 
Factor \\
Scores \\
\end{tabular}} & \multicolumn{3}{|c|}{2008} \\
\hline & 1 & 2 & 3 \\
\hline January & 6 & 41 & 3 \\
\hline February & 28 & 26 & 87 \\
\hline March & 181 & 173 & 224 \\
\hline April & 36 & 8 & 64 \\
\hline May & 58 & 33 & 59 \\
\hline June & 31 & 49 & 155 \\
\hline July & 64 & 48 & 246 \\
\hline August & 135 & 97 & 219 \\
\hline September & 58 & 75 & 127 \\
\hline October & 230 & 255 & 368 \\
\hline November & 192 & 604 & 89 \\
\hline December & 42 & 85 & 30 \\
\hline Total & 18 & 09 & 03 \\
\hline
\end{tabular}

Table 7. Category of Rainfall data with Cluster Centers

\begin{tabular}{|c|c|c|c|}
\hline \multirow{2}{*}{$\begin{array}{l}\text { Factor } \\
\text { Scores }\end{array}$} & \multicolumn{3}{|c|}{2010} \\
\hline & 1 & 2 & 3 \\
\hline January & 10 & 33 & 7 \\
\hline February & 1 & 0 & 0 \\
\hline March & 10 & 2 & 1 \\
\hline April & 30 & 16 & 24 \\
\hline May & 124 & 103 & 108 \\
\hline June & 191 & 91 & 65 \\
\hline July & 327 & 63 & 76 \\
\hline August & 308 & 156 & 88 \\
\hline September & 194 & 134 & 110 \\
\hline October & 185 & 187 & 149 \\
\hline November & 257 & 448 & 297 \\
\hline December & 122 & 295 & 98 \\
\hline Total & 02 & 07 & 21 \\
\hline
\end{tabular}

Table 2. Category of Rainfall data with Cluster Centers

\begin{tabular}{|c|c|c|c|}
\hline \multirow{2}{*}{$\begin{array}{l}\text { Factor } \\
\text { Scores }\end{array}$} & \multicolumn{3}{|c|}{2005} \\
\hline & 1 & 2 & 3 \\
\hline January & 4 & 322 & 0 \\
\hline February & 13 & 22 & 2 \\
\hline March & 31 & 29 & 9 \\
\hline April & 139 & 76 & 113 \\
\hline May & 77 & 269 & 30 \\
\hline June & 36 & 525 & 30 \\
\hline July & 86 & 329 & 109 \\
\hline August & 81 & 85 & 85 \\
\hline September & 96 & 166 & 136 \\
\hline October & 266 & 199 & 679 \\
\hline November & 268 & 597 & 532 \\
\hline December & 124 & 178 & 413 \\
\hline Total & 20 & 07 & 03 \\
\hline
\end{tabular}

Table 4. Category of Rainfall data with Cluster Centers

\begin{tabular}{|c|c|c|c|}
\hline \multirow{2}{*}{$\begin{array}{l}\text { Factor } \\
\text { Scores }\end{array}$} & \multicolumn{3}{|c|}{2007} \\
\hline & 1 & 2 & 3 \\
\hline January & 3 & 0 & 7 \\
\hline February & 15 & 12 & 4 \\
\hline March & 2 & 0 & 1 \\
\hline April & 29 & 23 & 68 \\
\hline May & 46 & 27 & 50 \\
\hline June & 173 & 36 & 56 \\
\hline July & 236 & 78 & 63 \\
\hline August & 254 & 195 & 110 \\
\hline September & 169 & 91 & 69 \\
\hline October & 261 & 360 & 192 \\
\hline November & 92 & 98 & 77 \\
\hline December & 227 & 350 & 181 \\
\hline Total & 02 & 06 & 21 \\
\hline
\end{tabular}

Table 6. Category of Rainfall data with Cluster Centers

\begin{tabular}{|l|c|c|c|}
\hline \multicolumn{1}{|c|}{ Factor } & \multicolumn{3}{|c|}{$\mathbf{2 0 0 9}$} \\
\cline { 2 - 4 } Scores & $\mathbf{1}$ & $\mathbf{2}$ & $\mathbf{3}$ \\
\hline January & 2 & 26 & 5 \\
February & 0 & 0 & 0 \\
March & 98 & 61 & 23 \\
April & 46 & 40 & 37 \\
May & 143 & 30 & 68 \\
June & 184 & 16 & 34 \\
July & 636 & 25 & 44 \\
August & 234 & 117 & 87 \\
September & 212 & 87 & 124 \\
October & 162 & 70 & 57 \\
November & 658 & 539 & 272 \\
December & 73 & 325 & 75 \\
\hline Total & $\mathbf{0 1}$ & $\mathbf{0 6}$ & $\mathbf{2 3}$ \\
\hline
\end{tabular}

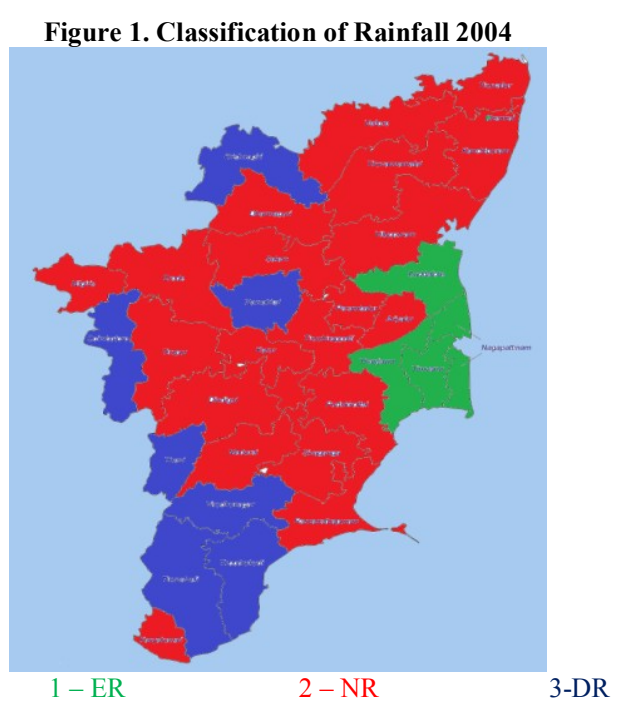



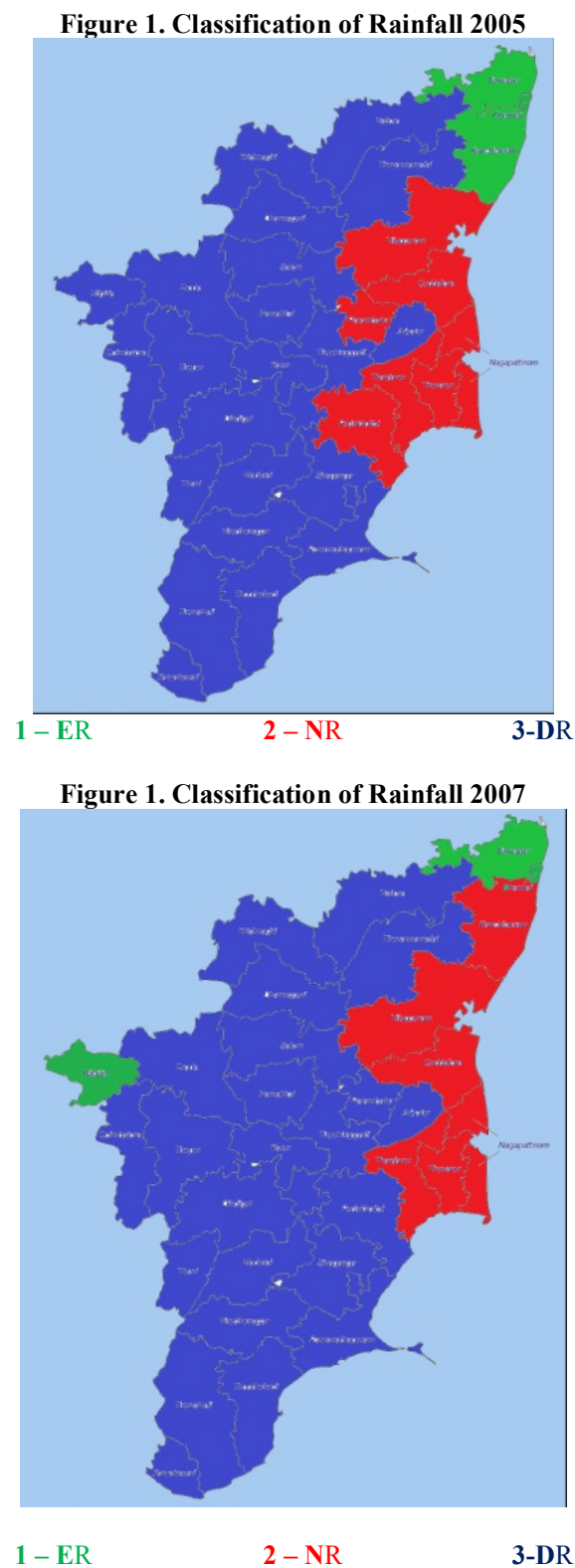

Figure 1. Classification of Rainfall 2008

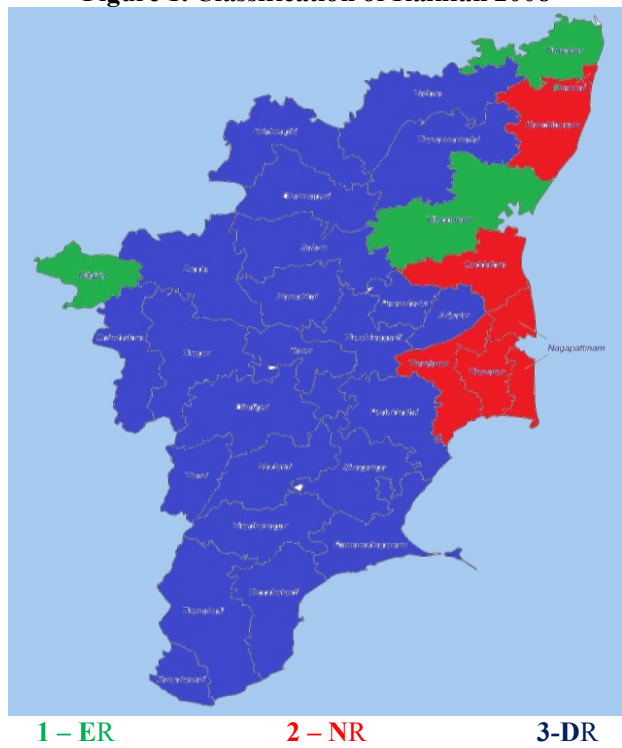

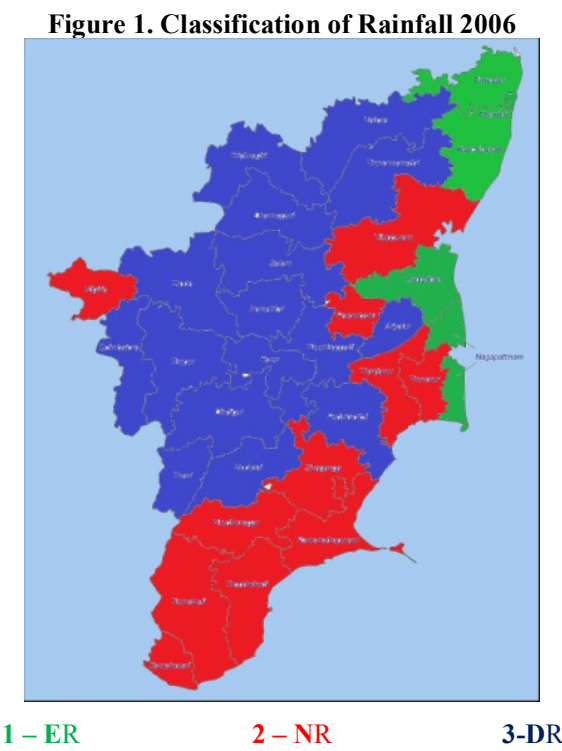

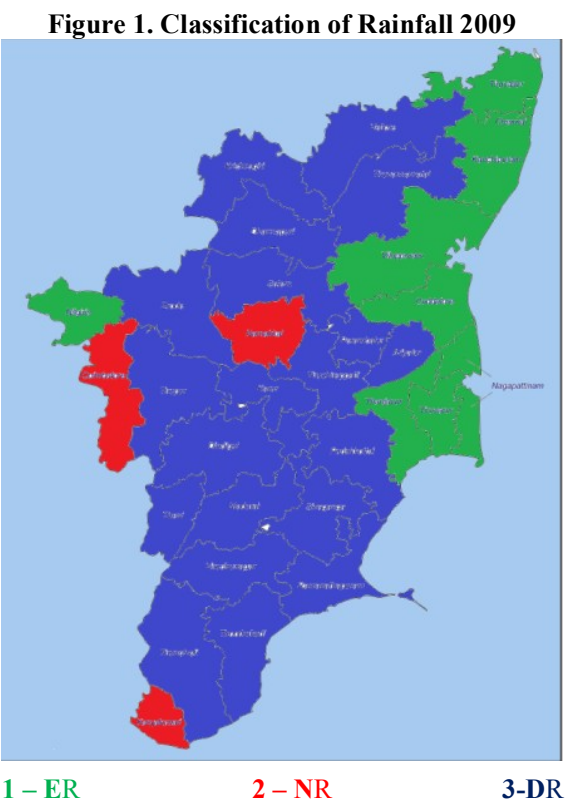

Figure 1. Classification of Rainfall 2010

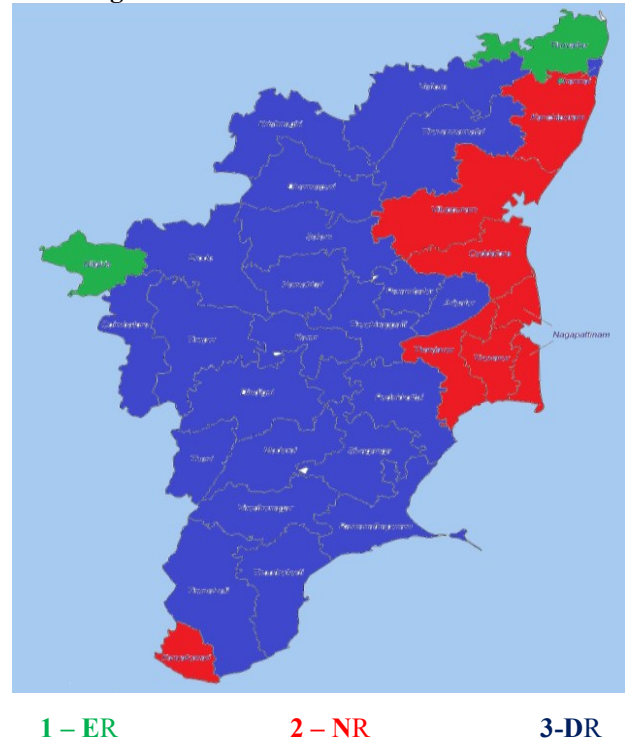




\section{Conclusion}

The purpose of this research is to identify the meaningful classification of rainfall data that are classified as best with respect to their rainfall in terms of monthly wise rainfall and data mining techniques. An attempt is made to analyze the rainfall data relating to various climate and monsoon period of seven years from 2004 to 2010. The present analysis has shown that only 3 groups could be meaningfully formed for each year. This indicates that only 3 types of rainfall existed over a period of seven years. Further, the year find them classified into Excess Rainfall (Group ER), Normal Rainfall (Group NR) and Deficient Rainfall (Group DR) categories depending on the climate and rainfall. In the year 2005 to 2010 Tamilnadu suffered with deficient rainfall, which is due to climate changes and global warming. In General, three monsoons seasons occur in every year and also the results achieved three groups of clusters. An overview of the results is under study to get an incorporated class of three sources of rainfall for any given year in Tamilnadu.

\section{References}

[1] Anderson T W (1984), An Introduction to Multivariate Statistical Analyis, 2/e, John Wiley and Sons, Inc., New York.

[2] M.C.Ramos.2001.Rainfall distribution pattern and their over time in a Mediterranean area. Theoretical and Applied Climatology.69.163170.

[3] Pramanik, S.K., and Jagannathan, P., (1954), Climate change in India - 1: rainfall. Indian Journal of Meteorology Geophysics , 4, 291-309.

[4] Parthasarathy, B., (1984), Inter annual and long term variability of Indian summer monsoon rainfall. In: Proceedings of the Indian Academy of Sciences (Earth Planetary Sciences), vol. 93, pp. 371-385.

[5] Parthasarathy, B., and Dhar, O.N., (1978), Climate Fluctuations Over Indian Region - Rainfall: a Review, vol. 31. Indian Institute of Tropical Meteorology, Pune. Research Report No. RR-025.

[6] Parthasarathy, B., Rupakumar, K., Munot, A.A., (1993), Homogeneous Indian monsoon rainfall: variability and prediction. In: Proceedings of the Indian Academy of Sciences (Earth Planetary Sciences), vol. 102, pp. 121-155

[7] Mooley, D.A., Parthasarathy, B., (1983), Variability of Indian summer monsoon rainfall and tropical circulation features. Monthly Weather Review, 111, 967-968.

[8] Rao K, PR. and Jagannathan,P.(1953). A study of the northeast monsoon rainfall of Tamil 31) Nadu; Indian journal of meteorology and Geophysics, 4:22.

[9] Thapliyal, V., Kulshrestha, S.M., (1991), Climate changes and trends over India. Mausam, 42, 333-338.

[10] Srivatsava, H.N., Dewan, B.N., Dikshit, S.K., Prakasa Rao, G.S., Singh, S.S., Rao, K.R., (1992), Decadal trends in climate over India. Mausam, 43, 7-20.

[11] Koteswaram, P., Alvi, S.M.A., (1969), Secular trends and periodicities in rainfall at west coast stations in India. Current Science, $101,371-375$.

[12] Jagannathan, P., Bhalme, H.N., (1973), Changes in pattern of distribution of southwest monsoon rainfall over India associated with sunspots. MonthlyWeather Review, 101, 691-700.

[13] Naidu, C.V., Srinivasa Rao, B.R., Bhaskar Rao, D.V., (1999), Climatic trends and periodicities of annual rainfall over India. Meteorological Application, 6, 395-404.

[14] Singh,N. and Sontakke, NA.(1999): On the variability and prediction of rainfall in the postmonsoon season over India; International journal of climatology, 19: 309 .

[15] Rupa Kumar, K., Pant, G.B., Parthasarathy, B., Sontakke, N.A., (1992), Spatial and sub-seasonal patterns of the long term trends of Indian summer monsoon rainfall. International Journal of Climatology, 12, 257-268.

\section{Author Profile}

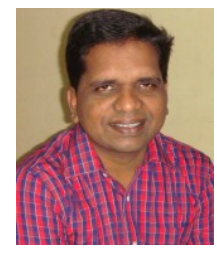

G. Manimannan received his M. Sc. M. Phil. Ph. D in Statistics from University of Madras, Chennai, India. He received PGDCA (Post Graduate Diploma in Computer Application) from Pondicherry University, Pondicherry, India. He has good research experience by working for many Project Guidance and consultation work in application of Statistics. He has published more than twenty nine research papers in various national and International journals. He is good in many programming languages like, FoxPro, HTML, COBOL, C, C++, VB, DBMS, SPSS, SYSSTAT, STATISTICA, MINITAB, MATLAB and working knowledge in SAS and R

R. Lakshmi Priya received her M. Sc. M. Phil. in Statistics from University of Madras, Chennai, India. She is Working as Assistant Professor in Statistics, Department of Statistics, Dr. Ambedkar Govt. Arts College, Vyasarpadi,Chennai. She has good knowledge in programming languages like, FORTRAN, PASCAL, COBOL, $\mathrm{C}, \mathrm{C}++, \mathrm{VB}$ and SPSS. 